\title{
Efficiency of bank crediting of real sector of economy in the context of separate banking groups: an empirical example from Ukraine
}

\author{
Vyacheslav V. Lyashenko \\ Laboratory "Transfer of Information Technologies in the Risk Reduction Systems", Faculty of Applied \\ Mathematics and Management, Kharkov National University of Radio Electronics, Ukraine \\ E-mail: lyashenko.vyacheslav@mail.ru
}

\begin{abstract}
Crediting is one of the basic directions of activity of banks. It is connected with that realisation of credit transactions should be considered as a defining component of bank management. According to this defining component each separate bank will organise loan of resources and their subsequent arrangement on proper conditions and on proper risk. Thus possibilities and the expediency of crediting are defined by a bank size in many respects. At the same time development of real sector of economy allows to speak about competitiveness, both individual industries of economy and the country as a whole. Hence, the efficiency of bank crediting of real sector of economy in the context of separate banking groups on example of Ukraine is investigated in this work. The given research is carried out with use of SFA methodology. There is also revealed the correlation between volumes of crediting of real sector of economy and efficiency of such crediting for separate banking groups. There was made the conclusion about necessity of balanced use of real resources of banks for growth of crediting efficiency.
\end{abstract}

Keywords: Modelling, Efficiency, Bank Crediting, Real Sector Of Economy, Stochastic Boundary Of Efficiency.

\section{Introduction}

The key role of banking sector of the economy will consist in forming and maintenance of necessary conditions for free redistribution of financial resources between various subjects of managing for the purpose of their sufficing (subjects of managing) in need of such resources. Thus such necessity consists in security of steady and stable functioning of all subjects of the managing which is taking part in such redistribution of financial resources and their further forward development. At the same time, special attention in processes of functioning of banking sector occupies crediting of real sector of economy. It is connected by that in system of modern economic relationships principal sources of loan are resources of banking sector of economy and equity market. Definition of a prevailing external source for attraction of additional resources is interconnected with disclosing of the concrete developed conditions of conducting economic activities in this or another country and availability to such sources from subjects of managing. However, as we can see from researches of various authors (Golodniuk, 2006; Smith, 2009; Stephan et al., 2011), owing to developed economic realities, for Ukraine more stable and reliable source of attraction of such activities are resources of banking sector of economy, rather than equity market resources. At the same time it is necessary to notice, that research of efficiency of crediting of real sector of economy as it is one of priority that proved by presence of big enough quantity of various works in the given direction (Quagliariello, 2009; Hsieh, 2002; Fisman and Love, 2003). Thus in such researches the attention is given both the analysis of possibilities and expediency of deriving of resources from a concrete source of their attraction, and the analysis of the developed credit conditions according to a condition of development of subjects of real sector of economy, in particular and a macroeconomic situation, in general.

As a whole it is necessary to underline, that the analysis of efficiency of bank crediting affects also various problem aspects in development of banking sector of economy, a banking system and bank efficiency which are the essential constituent of the general concept in research of economic processes and economic dynamics of concerned issues (Kuzemin and Lyashenko, 2008).

Thus, definition, disclosure and generalisation any of possible estimations of bank crediting is the important practical problem not only from a field of bank efficiency, but also economic development as a whole. It allows using such estimations for reviewing of efficiency of crediting of real sector of economy.

\section{Review, literature and substantiation of the main purpose of research}

One of the most recently considered directions, allowing to disclose and investigate efficiency of economic processes, occurrences, aspects of activity of various subjects of managing is the analysis with use of methods of econometric analysis among them it is necessary to select stochastic frontier analysis (SFA). Basis of SFA is a concept of engineering efficiency. According to research Farrell (1957) this efficiency allows to define an ability estimation to receive a maximum outcome (certain outcome), using a lot of inputs that uncover an aggregate of various factors of possibility of reaching of certain outcome (a maximum input). Thus the rapt 
attention to SFA is caused by that the given method allows to receive not only immediately estimations of efficiency in investigated area (efficiency of crediting, efficiency of the taxation, efficiency of development of separate aspects of production etc.), but also statistical estimations of parametres of considered model of boundary of efficiency. Thus SFA methodology allows comparing not only various models of boundaries of efficiency for investigated area, but also various data sets (taking into account their temporary component or a component characterising such data sets for various conditions of managing) for identical models of boundary of efficiency.

In particular Ataullah et al., (2004) analyze a modification of estimations of technical efficiency (further also simply effectivenesses) of banks efficiencies of India and Pakistan in their comparison. It is thus shown, that corresponding estimations of technical efficiency of banking sectors of both countries gradually improved throughout many years. Also Ataullah et al. notice that such modification of estimations of investigated technical efficiency happens differently for various banking groups.

Influence of separate banking groups upon the value of estimations of technical efficiency of their productivity is investigated in Lang and Welzel (1996) work on an example of data of German corporate banks. It is shown, that for all dimensional banking groups' moderate economy from a scale could be identified. Thus it is also noticed that growth of cumulative productivity of factors of production in a banking sector is higher for smaller on volume of assets of banks.

Hasan and Marton (2003) investigate functioning of the Hungarian banking sector during transient process from the centralised economy to market system of managing. The given analysis has allowed to draw a conclusion, that foreign banks and banks with the greatest participation of the foreign property in banks have great values of estimations of efficiency of their functioning in comparison with remaining banks.

Cuesta and Orea (2002) also considered a modification of investigated estimations of technical efficiency on an example of the Spanish saving banks depending on separation of such banks on certain groups. Similar researches are presented in Boutheina and Moez work (2013) too.

Thus, it is possible to draw a conclusion that influence of separate banking groups upon a modification of different considered estimations of technical efficiency in a field of bank activity is the one of directions in research of a condition of functioning both separate banks and development of banking sector. Thus it is necessary to note, first of all, influence of a size of investigated banks upon values of estimations of considered indicators of technical efficiency. For example, Nicholas and Effrosyni (2011), investigating efficiency of a banking system on an example of eight European countries, draw a direct conclusion about necessity of acceptance for attention of a size of banks, otherwise efficiency can tend to distortion of its estimations.

If we speak about technical efficiency of bank crediting it is necessary to note works: Gambacorta (2005) where problems of efficiency of bank crediting depending on a realised monetary and credit policy are investigated. However we can draw a conclusion, that the bank size is not actual and does not appreciably influence upon efficiency of crediting;

Berger and DeYoung (1997) which specify in that fact, that the received estimations of engineering efficiency of crediting could be the important indicator of the future problem credits and problem banks;

Vasyurenko et al. (2014) work shows comparative aspects of efficiency of bank crediting to natural persons and legal entities by banks of Ukraine.

Thus, the expediency of use of SFA methodology for disclosing of efficiency of crediting is conclusive. Based on aforecited analysis of references it is possible to state, that a main objective of the given work is an efficiency of bank crediting of real sector of economy in the context of separate banking groups. Thus as certain representations of disclosing of such research objective it is necessary to specify: calculation of estimations of technical effi- ciency of bank crediting in the context of separate banking groups; research of dynamics of a modification of the received estimations of technical efficiency of bank crediting for various banking groups in their comparative aspect.

\section{General SFA methodology}

For the purpose of disclosure of technical efficiency in the field of the analysis of banking activity the so-called boundary of efficiency is being formulated and it is characteristic for analysis methodology by stochastic boundaries. Essence of such methodology, according to transactionses Aigner et al. (1977), Battese and Coelli (1992), consists in: construction of boundary of efficiency of investigated process or an occurrence of methods of a statistical analysis in the form of some regressive association between the variables chosen for such analysis; positioning of investigated process, an occurrence or an object, concerning the obtained boundary of efficiency; definition of an estimation of efficiency of investigated process, an occurrence or an object in the form of the function characterising an accessibility of constructed boundary of efficiency which is represented for example in Jondrow et al. (1982) work:

$\mathrm{TE}_{\mathrm{i}}=\mathrm{e}^{-\mathrm{M}\left(\mathrm{u}_{\mathrm{i}} \mid \overline{\mathrm{\varepsilon}}_{\mathrm{i}}\right)}$,

Where

$\mathrm{TE}_{\mathrm{i}}-$ Technical efficiency of investigated process, an occurrence or an object $(\mathrm{i}, \mathrm{i}=\overline{1,1} 1 \mathrm{l}$ - total of investigated processes, occurrences or objects. In this case this amount is the investigated banks realising crediting of subjects of managing of real sector of economy);

$\mathrm{M}\left(\mathrm{u}_{\mathrm{i}} \mid \widehat{\varepsilon}_{\mathrm{i}}\right)$ - relative expectation value $\mathrm{u}_{\mathrm{i}}$ at estimated values $\widehat{\varepsilon}_{\mathrm{i}}$ which are complicated composite casual members of model for the obtained boundary of efficiency of investigated process, occurrence or object by means of statistical analysis methods:

$\mathrm{y}=\mathrm{f}(\mathrm{x}, \mathrm{B})+\varepsilon$,

$\varepsilon=\mathrm{v}-\mathrm{u}$,

Where

$\mathrm{y}$ - Vector of outcomes of investigated process, occurrence or object,

$\mathrm{X}$ - Vector of the resources used for receiving of outcomes of investigated process, occurrence or object,

f - function of boundary of efficiency of investigated process, occurrence or object,

B - Vector of parameters of function $\mathrm{f}$,

$\varepsilon$ - Complicated composite casual member of model who as a whole reflects a model error,

$\mathrm{v}$ - Vector of random variations of model,

$\mathrm{u}$ - Vector characterises a technical inefficiency of activity of investigated process, occurrence or object.

Based on a necessary condition of positive values of all component vectors $\mathrm{V}$ and $\mathrm{u}$ it is conjectured that these casual components of formalisation of model of boundary of efficiency can have the form of seminormal distribution $v \approx \mathrm{N}\left(0, \sigma_{v}^{2}\right)$ and $\mathrm{u} \approx \mathrm{N}_{+}\left(0, \sigma_{\mathrm{u}}^{2}\right)$ but by their values $\sigma_{\mathrm{v}}^{2}$ and $\sigma_{\mathrm{u}}^{2}$. Thus, considering unusual structure of errors of model of boundary of efficiency which has dissymetric distribution and consists of two components, regression residuals are estimated by a method of a maximum probability. Also it is necessary to notice that as a whole the model of function of boundary of efficiency of investigated processes, occurrences or objects for derivation of estimations of efficiency, can be defined in functional form of a transyllable or its simplified representation in Kobba-Duglasa functional form. 


\section{Used model of stochastic boundary of effi- ciency of crediting}

For the direct realisation of SFA methodology as a dependent variable the volumes of crediting of subjects of managing of real sector of economy are chosen in the context of every first of a considered aggregate of banks. As independent variables are considered: resources of other banks which are attracted by means of the market of interbank crediting; volume of borrowed funds in the form of deposits of natural and legal persons - clients of banks; volume of administrative and other operational expenditures of banks. As a whole the chosen variables completely correspond to variables of model of exposition of bank activity according to the intermediary approach which is based on the approach of assets (Golovan, 2006; Vasyurenko et al., 2014).

In the formalized aspect the given model has the following form: $\ln \left(\mathrm{KRF}_{\mathrm{i}}\right)=\mathrm{B}_{0}+\mathrm{B}_{1} \cdot \ln \left(\mathrm{DIB}_{\mathrm{i}}\right)+\mathrm{B}_{2} \cdot \ln \left(\mathrm{DPR}_{\mathrm{i}}\right)+\mathrm{B}_{3} \cdot \ln \left(\mathrm{AOV}_{\mathrm{i}}\right)$ $+\mathrm{v}_{\mathrm{i}}-\mathrm{u}_{\mathrm{i}}$,

Where

$\mathrm{KRF}_{\mathrm{i}}$ - Volumes of crediting of subjects of managing of real sector of economy in the context of every first of a considered aggregate of banks per certain date of time;

DIB $_{i}$ - resources of other banks which are attracted by means of the market of interbank in the context of every first of a considered aggregate of banks per certain date of time;

$\mathrm{DPR}_{\mathrm{i}}$ - Volume of borrowed funds in the form of deposits of natural and legal persons - clients of banks in the context of every first of a considered aggregate of banks per certain date of time;

$\mathrm{AOV}_{\mathrm{i}}$ - Volume of administrative and other operational expenditures in the context of every first of a considered aggregate of banks per certain date of time;

$\mathrm{B}_{0}, \mathrm{~B}_{1}, \mathrm{~B}_{2}, \mathrm{~B}_{3}-$ model factors.

Thus, for the constructed model of stochastic boundary of efficiency of crediting in the beginning we obtain estimations of technical efficiency of crediting for each bank from their analyzed aggregate. Then such banks are divided into certain groups, and the average estimation of technical efficiency of crediting of such groups is calculated according to the formula:

$$
\mathrm{STE}_{\mathrm{g}}=\frac{1}{\mathrm{Ng}} \cdot \sum_{\mathrm{ig}} \mathrm{TE}_{\mathrm{ig}} \text {, }
$$

Where

$\mathrm{STE}_{\mathrm{g}}$ - Average estimation of technical efficiency of crediting on a banking group $g$;

$\mathrm{Ng}$ - Amount of banks in group g ;

$\mathrm{TE}_{\mathrm{ig}}$ - Estimation of technical efficiency of crediting of the first bank in the group $g$.

Further the comparative analysis of average estimations of efficiency of crediting is carried out in the context of considered banking groups.

\section{Data for the analysis}

There are considered indicators of activity of various banks of Ukraine taken from the official site National to bank of Ukraine bank.gov.ua(http://www.bank.gov.ua/control/uk/publish/category? cat_id $=74208$ ) for realisation of the offered model of stochastic boundary of efficiency, for the purpose of receiving of corresponding estimations of efficiency of bank crediting of real sector of economy. The given reviewing concerns period since 2009 to 2012 taking into account their quarterly decomposition. In other words, we investigate quarterly efficiency of bank crediting of real sector of economy of Ukraine in 2009-2012. Such choice of data allows to analyse dynamics of a modification of effectiveness (in some way so-called retrospective show) of bank crediting starting from 16 separate time periods chosen for research. Thus each time period uses the various numbers of banks which varies from 148 to 157 banks. The certain amount of banks for each of considered separate period of time is caused by necessity of updating of initial sample of banks. State banks and the banks that have zero values of investigated parametres in model of stochastic boundary of efficiency have been excluded from initial sample of banks.

We consider separate banking groups according to their division in accordance with the method of National bank of Ukraine depending on sizes of their assets: I group - the greatest banks, II group - big banks, III group - middle banks and IV group - small banks. The first banking group has from 13 to 16 banks during investigated period of time, the second group - from 18 to 21 banks, the third group - from 18 to 24 banks and the fourth - from 91 to 103 banks.

Fig. 1 - fig. 4 shows a dynamics of the general structure for a banking system of Ukraine of the separate variables entering into model (4) according to chosen banking groups. Calculations are made on the basis of statistical data of National bank of Ukraine for separate banks.

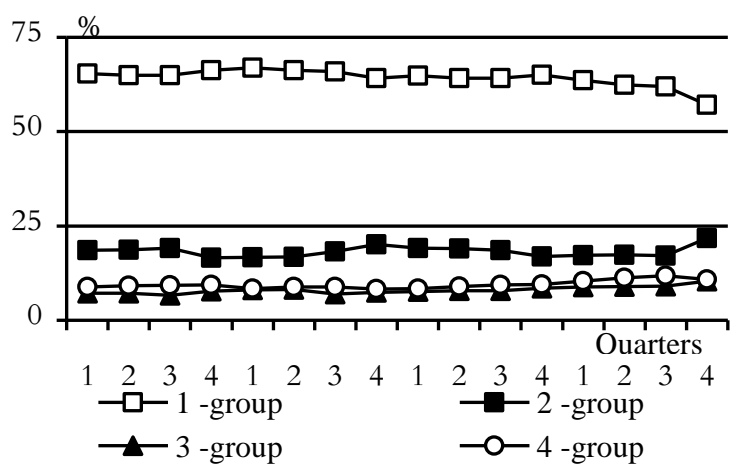

Fig. 1: Dynamics of a Modification of the General Structure of Volumes of Crediting of Real Sector of Economy in Ukraine According to the Chosen Banking Groups in Time Period from 2009 to 2012 in the Context of Separate Quarters.

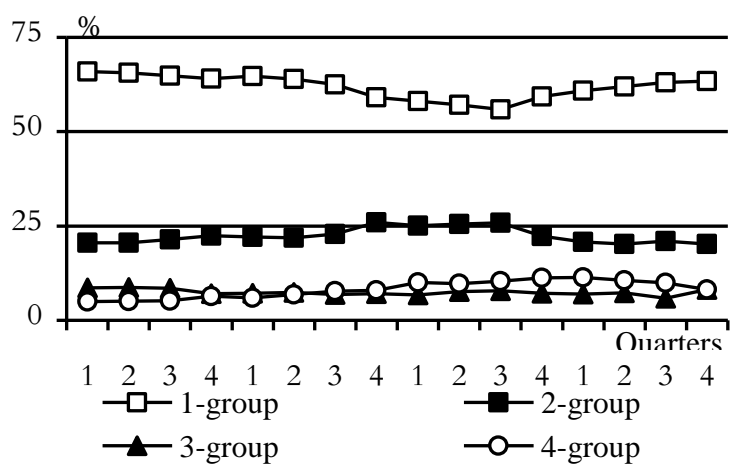

Fig. 2: Dynamics of A Modification of the General Structure of Resources of Other Banks Which are attracted by Means of the Market of Interbank Crediting according to the Chosen Banking Groups in Time Period from 2009 to 2012 in the Context of Separate Quarters.

Apparently from the presented data on fig. 1 - fig. 4 the greatest banks group has the greatest specific gravity in structure of considered variables of model (4) for definition of stochastic boundary of efficiency of crediting and its subsequent estimation. At the same time the dynamics of a specific gravity of various banking groups in structure of considered indicators of model (4) has the certain tendencies and it is mutually comparable, first of all, between 1 and 2 banking groups. 


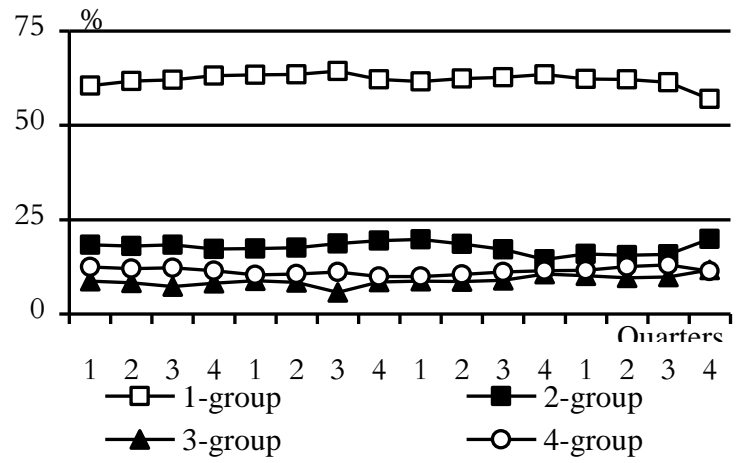

Fig. 3: Dynamics of a Modification of the General Structure of Volumes of Borrowed Funds in the Form of Deposits of Natural and Legal Persons - Clients of Banks According to the Chosen Banking Groups in Time Period from 2009 to 2012 in the Context of Separate Quarters.

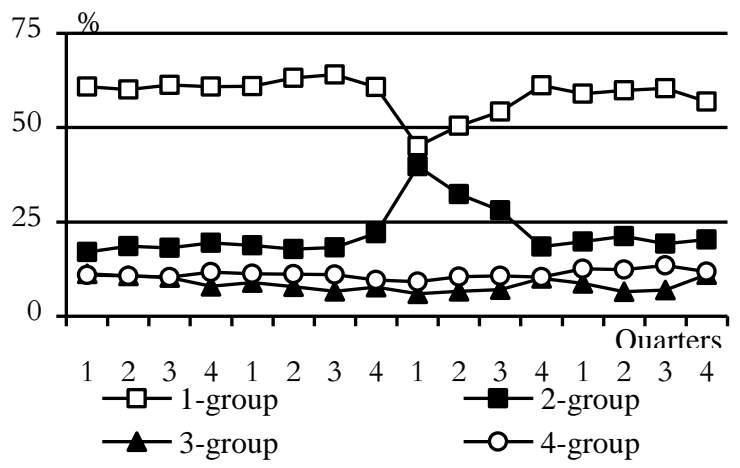

Fig. 4: Dynamics of a Modification of the General Structure of Volumes of Administrative and other Operational Expenditures According to the Chosen Banking Groups in Time Period from 2009 to 2012 in the Context of Separate Quarters.

\section{Estimations of efficiency of crediting}

For the purpose of calculation of estimations of efficiency of crediting according to model (4) on the basis of SFA methodology the software of CEPA corporation has been used (Centre for Efficiency and Productivity Analysis) -FRONTIER 4.1 program is free and it is in open access (http://www.uq.edu.au/economics/cepa/frontier.php). Outcomes of calculations are presented in the Table 1.

Parameter's and statistical values of outcomes of calculations are presented in the table 2 and the table 3 for investigated model (4) of stochastic boundary of efficiency in the context of separate quarters from considered period of time, namely:

Values of factors $B_{0} B_{1} \quad B_{2} \quad B_{3}$ of considered model and their statistical estimations - a standard error and t-ratio on a significance level 0, 05 for certain periods of time;

Value of a total dispersion of error $\sigma^{2}=\sigma_{v}^{2}+\sigma_{u}^{2}$ which defines key distribution parametres of random components of considered model and their statistical estimations - standard error and t-ratio on a significance level 0,05 for certain periods of time;

Value of a share of an ineffective component $\gamma=\sigma_{u}^{2} / \sigma^{2}$ in a total dispersion of error and their statistical estimations - standard error and t-ratio on a significance level 0,05 for certain periods of time; Value of function of the logarithm of a maximum probability (LR) for certain periods of time; amount of considered banks in certain periods of time.

Table 1: Mean Values of Estimations of Efficiency of Crediting of Real Sector of Economy in Ukraine in the Context of Separate Banking Groups

\begin{tabular}{|c|c|c|c|c|c|}
\hline \multirow{2}{*}{\multicolumn{2}{|c|}{$\begin{array}{l}\text { Time period of } \\
\text { research }\end{array}$}} & \multicolumn{4}{|c|}{$\begin{array}{l}\begin{array}{l}\text { Values of estimations of efficiency for separate banking } \\
\text { groups }\end{array} \\
\end{array}$} \\
\hline & & 1 & 2 & 3 & 4 \\
\hline \multirow{4}{*}{ ஓి } & 1 Quarter & 0,72 & 0,67 & 0,59 & 0,59 \\
\hline & 2 Quarter & 0,71 & 0,64 & 0,58 & 0,58 \\
\hline & 3 Quarter & 0,74 & 0,68 & 0,64 & 0,64 \\
\hline & 4 Quarter & 0,66 & 0,55 & 0,59 & 0,53 \\
\hline \multirow{4}{*}{$\stackrel{\circ}{\stackrel{0}{\circ}}$} & 1 Quarter & 0,65 & 0,56 & 0,58 & 0,51 \\
\hline & 2 Quarter & 0,69 & 0,60 & 0,64 & 0,57 \\
\hline & 3 Quarter & 0,66 & 0,61 & 0,63 & 0,58 \\
\hline & 4 Quarter & 0,66 & 0,59 & 0,58 & 0,54 \\
\hline \multirow{4}{*}{$\bar{\Xi}$} & 1 Quarter & 0,65 & 0,56 & 0,54 & 0,50 \\
\hline & 2 Quarter & 0,63 & 0,57 & 0,54 & 0,49 \\
\hline & 3 Quarter & 0,65 & 0,59 & 0,53 & 0,50 \\
\hline & 4 Quarter & 0,64 & 0,60 & 0,51 & 0,50 \\
\hline \multirow{4}{*}{$\stackrel{\text { ก }}{\stackrel{2}{\sim}}$} & 1 Quarter & 0,64 & 0,56 & 0,48 & 0,46 \\
\hline & 2 Quarter & 0,57 & 0,49 & 0,47 & 0,41 \\
\hline & 3 Quarter & 0,57 & 0,48 & 0,49 & 0,43 \\
\hline & 4 Quarter & 0,52 & 0,49 & 0,49 & 0,44 \\
\hline
\end{tabular}

Table 2: Parameter's and Statistical Values of Outcomes of Calculations for the Presented Model of Stochastic Boundary of Efficiency.

\begin{tabular}{|c|c|c|c|c|c|c|c|c|c|}
\hline \multirow{2}{*}{\multicolumn{2}{|c|}{ Parametres }} & \multicolumn{3}{|c|}{ Quarters of 2009} & \multicolumn{5}{|c|}{ Quarters of 2010} \\
\hline & & 1 & 2 & 3 & 4 & 1 & 2 & 3 & 4 \\
\hline \multirow{3}{*}{$\mathrm{B}_{0}$} & coeff. & 2,25 & 2,79 & 2,49 & 2,62 & 2,62 & 2,60 & 2,66 & 1,77 \\
\hline & st.-error & 0,37 & 0,43 & 0,43 & 0,48 & 0,54 & 0,42 & 0,55 & 0,45 \\
\hline & t-ratio & 6,02 & 6,49 & 5,74 & 5,46 & 4,899 & 6,14 & 4,81 & 3,97 \\
\hline \multirow{3}{*}{$\mathrm{B}_{1}$} & coeff. & 0,11 & 0,18 & 0,20 & 0,19 & 0,139 & 0,24 & 0,38 & 0,27 \\
\hline & st.-error & 0,02 & 0,03 & 0,03 & 0,03 & 0,034 & 0,03 & 0,05 & 0,03 \\
\hline & t-ratio & 5,52 & 5,49 & 6,85 & 6,02 & 4,120 & 7,93 & 8,44 & 7,87 \\
\hline \multirow{3}{*}{$\mathrm{B}_{2}$} & foff & 0,58 & 0,50 & 0,53 & 0,56 & 0,626 & 0,59 & 0,36 & 0,62 \\
\hline & st.-error & 0,05 & 0,06 & 0,07 & 0,06 & 0,071 & 0,06 & 0,08 & 0,07 \\
\hline & t-ratio & 10,77 & 8,39 & 8,16 & 9,08 & 8,849 & 9,19 & 4,65 & 9,29 \\
\hline \multirow{3}{*}{$\mathrm{B}_{3}$} & coeff. & 0,27 & 0,23 & 0,18 & 0,15 & 0,156 & 0,07 & 0,17 & 0,06 \\
\hline & st.-error & 0,06 & 0,07 & 0,07 & 0,08 & 0,086 & 0,07 & 0,09 & 0,08 \\
\hline & t-ratio & 4,23 & 3,33 & 2,41 & 2,01 & 1,813 & 1,03 & 2,03 & 0,87 \\
\hline \multirow{3}{*}{$\sigma^{2}$} & coeff. & 0,67 & 0,78 & 0,59 & 1,10 & 1,221 & 0,79 & 0,89 & 0,91 \\
\hline & st.-error & 0,12 & 0,14 & 0,12 & 0,19 & 0,210 & 0,15 & 0,19 & 0,16 \\
\hline & t-ratio & 5,69 & 5,74 & 4,99 & 5,96 & 5,802 & 5,45 & 4,49 & 5,81 \\
\hline \multirow{3}{*}{$\gamma$} & coeff. & 0,78 & 0,77 & 0,63 & 0,83 & 0,800 & 0,79 & 0,65 & 0,88 \\
\hline & st.-error & 0,08 & 0,08 & 0,14 & 0,06 & 0,075 & 0,09 & 0,16 & 0,06 \\
\hline & t-ratio & 9,51 & 9,30 & 4,61 & 13,03 & 10,72 & 9,14 & 4,14 & 15,57 \\
\hline \multirow{2}{*}{\multicolumn{2}{|c|}{$\begin{array}{c}\log \mathrm{LR} \\
\text { amount of consid- } \\
\text { ered banks }\end{array}$}} & $-133,51$ & $-148,88$ & $-139,61$ & $-167,48$ & $-173,25$ & $-144,69$ & $-162,36$ & $-141,97$ \\
\hline & & 157 & 157 & 156 & 157 & 152 & 154 & 149 & 154 \\
\hline
\end{tabular}

Table 1 data show that values of estimations of efficiency of crediting of real sector of economy in Ukraine in the context of separate banking groups decreases. Thus the greatest decrease is observed for the $1^{\text {st }}$ banking group which has made $28,63 \%$. The least decrease of estimations of efficiency of crediting of real sector of economy is observed for the $3^{\text {rd }}$ banking groups which has made $15,96 \%$. 
Table 3: Parameter's and Statistical Values of Outcomes of Calculations for the Presented Model of Stochastic Boundary of Efficiency.

\begin{tabular}{|c|c|c|c|c|c|c|c|c|c|}
\hline \multirow{2}{*}{\multicolumn{2}{|c|}{ Parametres }} & \multicolumn{5}{|c|}{ Quarters of 2011} & \multicolumn{3}{|c|}{ Quarters of 2012} \\
\hline & & 1 & 2 & 3 & 4 & 1 & 2 & 3 & 4 \\
\hline \multirow{3}{*}{$\mathrm{B}_{0}$} & oeff. & 1,85 & 2,42 & 2,45 & 2,42 & 3,07 & 3,89 & 3,71 & 3,25 \\
\hline & st.-error & 0,49 & 0,62 & 0,54 & 0,54 & 0,58 & 0,65 & 0,58 & 0,59 \\
\hline & 110 & 3,77 & 3,89 & 4,58 & 4,50 & 5,31 & 6,01 & 6,39 & 5,47 \\
\hline \multirow{3}{*}{$\mathrm{B}_{1}$} & coeff. & 0,27 & 0,21 & 0,25 & 0,09 & 0,09 & 0,09 & 0,13 & 0,15 \\
\hline & st.-error & 0,04 & 0,04 & 0,04 & 0,04 & 0,04 & 0,05 & 0,04 & 0,04 \\
\hline & t-ratio & 7,65 & 4,98 & 5,88 & 2,34 & 2,35 & 1,69 & 3,73 & 3,82 \\
\hline \multirow{3}{*}{$\mathrm{B}_{2}$} & coeff. & 0,69 & 0,65 & 0,65 & 0,66 & 0,72 & 0,57 & 0,49 & 0,49 \\
\hline & st.-error & 0,07 & 0,09 & 0,08 & 0,08 & 0,08 & 0,09 & 0,07 & 0,06 \\
\hline & t-ratio & 9,84 & 7,14 & 8,04 & 8,27 & 8,82 & 5,97 & 6,94 & 8,49 \\
\hline \multirow{3}{*}{$\mathrm{B}_{3}$} & coeff. & $-0,04$ & 0,05 & 0,01 & 0,16 & 0,03 & 0,18 & 0,23 & 0,24 \\
\hline & st.-error & 0,09 & 0,11 & 0,01 & 0,09 & 0,09 & 0,11 & 0,08 & 0,07 \\
\hline & t-ratio & $-0,47$ & 0,46 & 0,02 & 1,79 & 0,37 & 1,66 & 2,76 & 3,27 \\
\hline \multirow{3}{*}{$\sigma^{2}$} & coeff. & 1,23 & 1,39 & 1,27 & 1,31 & 1,72 & 2,74 & 2,46 & 2,34 \\
\hline & st.-error & 0,19 & 0,24 & 0,21 & 0,21 & 0,26 & 0,38 & 0,35 & 0,33 \\
\hline & t-ratio & 6,36 & 5,71 & 6,19 & 6,20 & 6,62 & 7,26 & 6,99 & 7,09 \\
\hline \multirow{3}{*}{$\gamma$} & coeff. & 0,90 & 0,79 & 0,84 & 0,85 & 0,91 & 0,91 & 0,94 & 0,94 \\
\hline & st.-error & 0,04 & 0,08 & 0,06 & 0,06 & 0,04 & 0,03 & 0,03 & 0,02 \\
\hline & t-ratio & 20,96 & 10,39 & 14,91 & 15,41 & 23,76 & 31,37 & 34,44 & 38,96 \\
\hline \multirow{2}{*}{\multicolumn{2}{|c|}{$\begin{array}{l}\text { amount of consid- } \\
\text { ered banks }\end{array}$}} & $-161,44$ & $-186,91$ & $-173,19$ & $-171,16$ & $-186,19$ & $-221,94$ & $-205,88$ & $-192,53$ \\
\hline & & 154 & 154 & 154 & 151 & 155 & 156 & 154 & 148 \\
\hline
\end{tabular}

Fig. 5 and fig. 6 show dependence between volumes of crediting of real sector of economy and efficiency of crediting for $1^{\text {st }}$ and $3^{\text {rd }}$ banking groups in Ukraine accordingly.

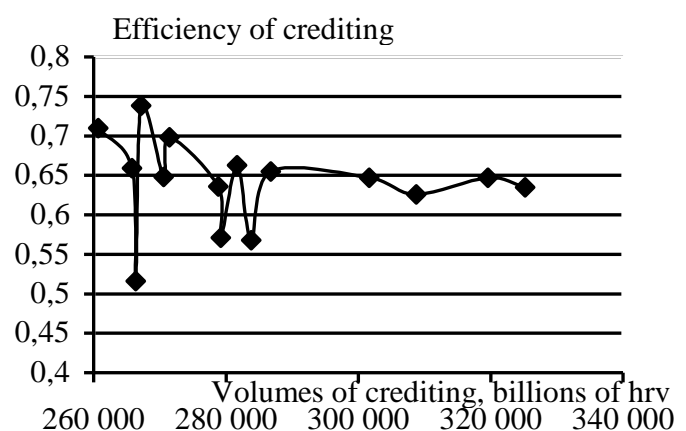

Fig. 5: Dependence between Volumes of Crediting Of Real Sector of Economy and Efficiency of Crediting For $1^{\text {st }}$ Banking Group in Ukraine.

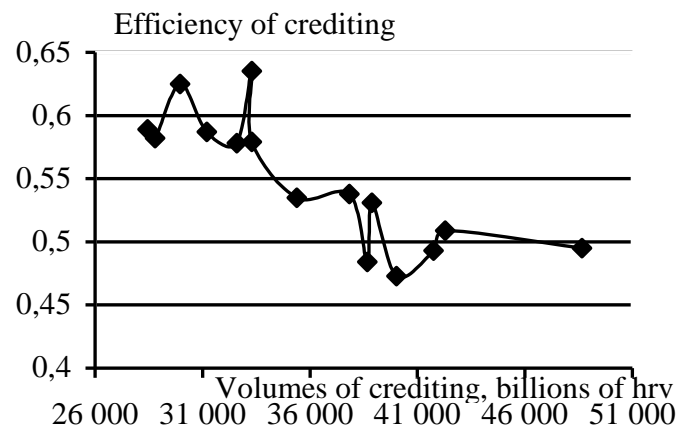

Fig. 6: Dependence between Volumes of Crediting of Real Sector of Economy and Efficiency of Crediting for $3^{\text {rd }}$ Banking Groups in Ukraine
From data of fig. 5 we can see, that for the $1^{\text {st }}$ banking group across Ukraine dependence between volumes of crediting of real sector of economy and efficiency of crediting as a result of growth of volumes of crediting mainly occurs the variation of the obtained estimations of efficiency of crediting concerning some magnitude. In particular for investigated period of time such variation of estimations of efficiency with magnification of volumes of crediting in the $1^{\text {st }}$ banking group in Ukraine are observed at level 0,65 and occurred in a range from 0,5 to 0,75 .

At the same time from data fig. 6 it is visible, that with growth of volumes of crediting the average estimation of efficiency of crediting in $3^{\text {rd }}$ banking group has the steady tendency to a decrease during investigated period of time. Most likely, it is connected with existing realities of conducting economic activities in Ukraine on investigated period of time (Vasyurenko et al., 2014).

Thus, it is possible to draw a conclusion that estimations of efficiency of crediting of $1^{\text {st }}$ banking group are steadier, rather than estimations of efficiency of crediting of $3^{\text {rd }}$ banking group in relation to a modification of volumes of granted credits to real sector of economy taking into account the developed realities of managing in Ukraine. Thus, in many respects such stability is defined by a size of separate banking groups which is characterised by volumes of their assets. If take in attention separate components of considered model of efficiency of crediting, it is possible to draw a conclusion that the $1^{\text {st }}$ banking group has more balanced correlation of dynamics of their resource base (in the form of resources of other banks, which are attracted by means of the market of interbank crediting and volumes of borrowed funds in the form of deposits of natural and legal persons - clients of banks) and expenditures on service of such resource base and moneylending business of real sector of economy (in the form of volumes of administrative and other operational expenditures), rather than for $3^{\text {rd }}$ banking groups. Hence, the basic problematics of the issue, concerning increase of efficiency of crediting lays in plane of an increase of equation of correlations of various indicators of bank activity that in many respects will be defined by bank sizes according to its assets.

\section{Conclusion}

Thus, the considered model of stochastic boundary of efficiency of crediting can be used for derivation of average estimations of efficiency of bank crediting of real sector of economy in the context of separate banking groups. In particular use of the offered model of stochastic boundary of efficiency of crediting allows to draw a conclusion about decrease of estimation of efficiency of bank crediting of real sector of economy in Ukraine for investigated period of time. It is shown, that the decrease of efficiency of bank crediting for investigated period of time is characteristic for all banking groups without dependence from volume of a portfolio of assets of separate banks which make such groups.

At the same time the work draws attention to that fact, that for the different investigated banking groups, dependences between volumes of crediting of real sector of economy and efficiency of crediting are various. In particular it is shown, that for banking group which includes banks with the greatest volumes of assets, more stable dependence between volumes of crediting of real sector of economy and efficiency of crediting is characteristic. Demonstration of such stability is the modification of efficiency of crediting within some range on an investigated period of time. For banking group which includes banks with smaller volumes of assets, the tendency to a decrease of estimation of efficiency of crediting of real sector to economy is characteristic at the general growth of volumes of crediting in the developed conditions of managing in Ukraine. Eventually, it has allowed to draw a conclusion: about expediency of reviewing of separate banking groups in research of efficiency of crediting of real sector of economy; significance in the given context of volumes of assets of the banks forming separate banking groups, for detection of existing correlations between volumes of crediting of real sector of economy and 
efficiency of such crediting which is also defined by magnitude of used bank resources for such purposes.

Also no less important problem is the question of increase of efficiency of processes of bank crediting of real sector of economy which is in a plane of adequacy and equation of use of real resources of banks.

\section{References}

[1] Aigner, D., Lovell, C. A. L., \& Schmidt, P. (1977). Formulation and estimation of stochastic frontier production function mod-els. Journal of econometrics, 6(1), 21-37. http://dx.doi.org/10.1016/0304-4076 (77)90052-5

[2] Ataullah, A., Cockerill, T., \& Le, H. (2004). Financial liberalization and bank efficiency: a comparative analysis of India and Pakistan. Applied Economics, 36(17), 1915-1924. http://dx.doi.org/10.1080/000368404200068638.

[3] Battese, G. E., \& Coelli, T. J. (1992). Frontier production functions, technical efficiency and panel data: with application to paddy farmers in India. Journal of productivity analysis, 3(1-2), 153-169. http://dx.doi.org/10.1007/BF00158774.

[4] Berger, A. N., \& DeYoung, R. (1997). Problem loans and cost efficiency in commercial banks. Journal of Banking \& Finance, 21(6), 849-870. http://dx.doi.org/10.1016/S0378-4266 (97)00003-4.

[5] Boutheina, B., \& Moez, L. (2013). Efficiency of the Tunisian trade banks: Study by the stochastic frontier ap-proach. Panoeconomicus 60(1), 103-132. http://dx.doi.org/10.2298/PAN1301103B

[6] Cuesta, R. A., \& Orea, L. (2002). Mergers and technical efficiency in Spanish savings banks: A stochastic distance function approach. Journal of Banking \& Finance, 26(12), 2231-2247. http://dx.doi.org/10.1016/S0378-4266 (01)00184-4.

[7] Farrell, M. J. (1957). The measurement of productive efficien-cy. Journal of the Royal Statistical Society. Series A (Gen-eral), 120(3), 253-290. http://dx.doi.org/10.2307/2343100.

[8] Fisman, R., \& Love, I. (2003). Trade credit, financial intermediary development, and industry growth. The Journal of Finance, 58(1) 353-374. http://dx.doi.org/10.1111/1540-6261.00527.

[9] Gambacorta, L. (2005). Inside the bank lending channel. European Economic Review, 49(7), 1737-1759. http://dx.doi.org/10.1016/j.euroecorev.2004.05.004.

[10]Golodniuk, I. (2006). Evidence on the bank-lending channel in Ukraine. Research in International Business and Finance, 20(2), 180 199. http://dx.doi.org/10.1016/j.ribaf.2005.09.007.

[11]Golovan, S. V. (2006). Factors affecting the efficiency of Russian banks. Journal of Applied Econometrics, 2, 3-17.

[12]Hasan, I., \& Marton, K. (2003). Development and efficiency of the banking sector in a transitional economy: Hungarian experience. Journal of Banking \& Finance, 27(12), 2249-2271. http://dx.doi.org/10.1016/S0378-4266 (02)00328-X.

[13]Hsieh, C. T. (2002). What explains the industrial revolution in Eas Asia? Evidence from the factor markets. The American Economic Re view, 92(3), 502-526. http://dx.doi.org/10.1257/00028280260136372.

[14]Jondrow, J., Knox Lovell, C. A., Materov, I. S., \& Schmidt, P. (1982). On the estimation of technical inefficiency in the stochastic frontier production function model. Journal of econometrics, 19(2), 233-238. http://dx.doi.org/10.1016/0304-4076 (82)90004-5.

[15]Kuzemin, A., \& Lyashenko, V. (2008). Analysis of Spatial-temporal Dynamics in the System of Economic Security of Different Subjects of Economic Management. International Journal Information Technologies and Knowledge, 2(3), 234-238.

[16]Lang, G., \& Welzel, P. (1996). Efficiency and technical progress in banking Empirical results for a panel of German cooperative banks. Journal of Banking \& Finance, 20(6), 1003-1023. http://dx.doi.org/10.1016/0378-4266 (95)00040-2.

[17]Nicholas, A., \& Effrosyni, A. (2011). Bank efficiency: Evidence from a panel of European banks. Panoeconomicus, 58(3), 329-341. http://dx.doi.org/10.2298/PAN1103329A

[18]Quagliariello, M. (2009). Macroeconomic uncertainty and banks' lending decisions: the case of Italy. Applied Economics, 41(3), 323336. http://dx.doi.org/10.1080/00036840601007286.

[19]Smith, G. (2009). Martingales in European emerging stock markets: Size, liquidity and market quality. The European Journal of Finance, 15(3), 249-262. http://dx.doi.org/10.1080/13518470802423262.

[20]Stephan, A., Talavera, O., \& Tsapin, A. (2011). Corporate debt maturity choice in emerging financial markets. The Quarterly Review of Economics and Finance, 51(2), 141-151. http://dx.doi.org/10.1016/j.qref.2010.12.003.
[21] Vasyurenko, O., Lyashenko, V., \& Podchesova V. (2014). Efficiency of lending to natural persons and legal entities by banks of Ukraine: methodology of stochastic frontier analysis. Herald of the National Bank of Ukraine, 1, 5-11. 